\title{
Analysis of $\mathrm{Cl}$...Cl and $\mathrm{C}-\mathrm{H}$...Cl intermolecular interactions involving chlorine in substituted 2-chloroquinoline derivatives
}

\author{
VENKATESHA R HATHWAR $^{\mathrm{a}}, \mathrm{S}_{\text {MOHANA ROOPAN }}^{\mathrm{b}}, \mathrm{R}^{\mathrm{R}}$ SUBASHINI $^{\mathrm{b}}$, \\ F NAWAZ KHAN ${ }^{\mathrm{b}}$ and T N GURU ROW ${ }^{\mathrm{a}, *}$ \\ ${ }^{a}$ Solid State and Structural Chemistry Unit, Indian Institute of Science, Bangalore 560012 \\ ${ }^{\mathrm{b}}$ Organic Chemistry Division, School of Advanced Sciences, Vellore Institute of Technology University, \\ Vellore 632014 \\ e-mail: ssctng@sscu.iisc.ernet.in
}

\begin{abstract}
Six crystal structures of substituted 2-chloroquinoline derivatives have been analysed to evaluate the role of $\mathrm{Cl}$ atom as a self recognizing unit resulting in the formation of $\mathrm{Cl} \ldots \mathrm{Cl}$ and $\mathrm{C}-\mathrm{H} \ldots \mathrm{Cl}$ interactions to generate supramolecular assembly in the solid state. The features of Type I and Type II geometries associated with $\mathrm{Cl} \ldots \mathrm{Cl}$ interactions have been analysed to show directional preferences leading to differences in the packing motifs in these crystal structures. $\mathrm{C}-\mathrm{H}$... $\mathrm{Cl}$ interactions are generated exclusively in structures depicting Type $\mathrm{II} \mathrm{Cl} \ldots \mathrm{Cl}$ interaction have been observed in these structures.
\end{abstract}

Keywords. Intermolecular interactions; halogen...halogen contacts; $\mathrm{C}-\mathrm{H} \ldots \mathrm{Cl}$ hydrogen bonds; supramolecular assemblies.

\section{Introduction}

The presence of halogen atom, in particular chlorine in place of methyl group on simple aromatic compounds has been shown to significantly alter the crystal structure. ${ }^{1}$ Even though both chlorine and methyl groups are of similar size and occupy about the same volume, dichloro substitution on aromatic molecules produce crystal structures with one of the axis being $4 \AA .^{2}$ Recent $a b$ initio calculations show that halogen...halogen contacts are controlled by electrostatic forces and indeed display directional preferences. ${ }^{3}$ In a recent article, concerning overcrowding of halogens as in the case of hexachlorobenzene, both chemical and geometrical models appear to dictate halogen... halogen interactions. ${ }^{4}$ In general $\mathrm{C}-\mathrm{X}_{1} \ldots \mathrm{X}_{2}-\mathrm{C}$ contacts are classified into two types with $\theta_{1}=\mathbf{C}-\mathbf{X}_{1} \ldots \mathbf{X}_{2}$ and $\theta_{2}=\mathbf{X}_{1} \ldots \mathbf{X}_{2}-\mathbf{C}$ and $d=\mathrm{X}_{1} \cdots \mathrm{X}_{2}$ distance as Type I (cis or trans geometry) and Type II (L geometry) (scheme 1 ). ${ }^{5}$

If the angles are nearly similar, $\theta_{1} \cong \theta_{2}$ the geometry is associated with Type I whereas $\theta_{1} \cong 180^{\circ}$ and $\theta_{2} \cong 90^{\circ}$ represents Type II geometry. Desiraju et al have demonstrated that Type II contacts dominate in case of $\mathrm{X}=\mathrm{I}$ whereas Type I dominate in case of $\mathrm{X}=\mathrm{Cl}$ with $\mathrm{X}=\mathrm{Br}$ displaying both types of geome-

*For correspondence tries. ${ }^{6}$ In case of F, it is generally observed that $\mathrm{C}-\mathrm{H} \ldots \mathrm{F}$ interactions prevail over $\mathrm{F} \ldots \mathrm{F}$ interactions. ${ }^{7}$ However, this feature is disputed both from theory and more recently with large number of experimental observations showing preferences to the formation of F ...F interactions. ${ }^{8}$ It has become obviously clear that halogen...halogen interaction could very well be utilized as a design element in crystal engineering. Recent studies on the experimental charge density analysis on the nature of $\mathrm{Cl} \ldots \mathrm{Cl}$ interaction has demonstrated that Type II contacts may be understood as a interaction between electrophilic and nucleophilic region between adjacent halogen atom, a feature which unambiguously sup-

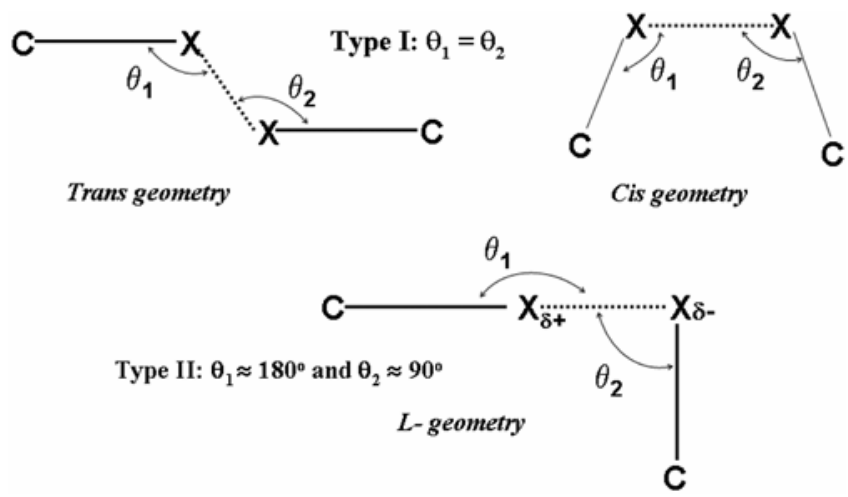

Scheme 1. Schematic representation of Type I (cis and trans geometries) and Type II (L geometry) halogen... halogen contacts. 
port attractive nature of $\mathrm{Cl} \ldots \mathrm{Cl}$ interactions. ${ }^{9} \mathrm{We}$ have recently shown by in situ cryo-crystallization technique that the structure of 2-chloro aniline (low melting organic liquid) is stabilized via $X_{3}$ synthon resulting in a helical motif along the $3_{1}$ axis. ${ }^{10}$

In this article, we have determined the crystal structure of six 2-chloroquinoline derivatives (scheme 2) and have analysed the directional preference in $\mathrm{Cl} \ldots \mathrm{Cl}$ interaction in terms of crystal packing and have analysed the propensity of the formation of $\mathrm{C}-\mathrm{H} \ldots \mathrm{Cl}$ contacts in both Type I and Type II geometries. All the six structures are heterocyclic derivatives constituting an interesting class of compounds with synthetic versatility and effective biological activities. Indeed, quinoline and their derivatives have remarkable pharmacological activities and widely used as antiallergic, ${ }^{11}$ antimalarial ${ }^{12}$ antibacterial,,$^{13}$ antiproliferative, ${ }^{14}$ anticancer ${ }^{15}$ and antiparasitic ${ }^{16}$ compounds.

\section{Experimental}

\subsection{Synthesis}

2.1a Compound QN1: 2,4-dichloro 5-methyl quinoline: 3-Methylaniline $(1 \mathrm{mmol})$, malonic acid $(1 \mathrm{mmol})$ and $10 \mathrm{ml}$ of dry $\mathrm{POCl}_{3}$ were taken in a $\mathrm{RB}$ flask and the resulting mixture was heated at $453 \mathrm{~K}$ for $1 \mathrm{~h}$. The reaction mixture after completion of reaction (monitored by TLC) was poured into the crushed ice and residue containing mixture of iso-

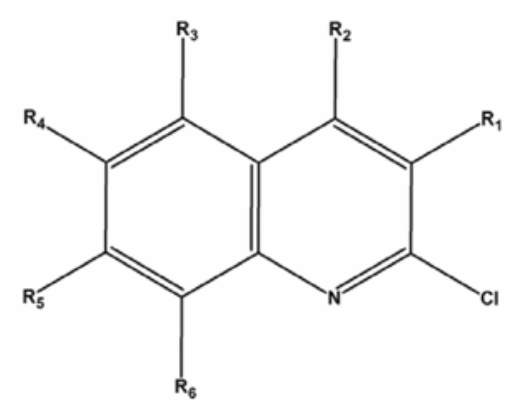

Scheme 2. (i) Compound QN1 where $\mathrm{R}_{2}=\mathrm{Cl}, \mathrm{R}_{3}=$ Methyl $\left(\mathrm{CH}_{3}\right) ; \quad \mathrm{R}_{1}=\mathrm{R}_{4}=\mathrm{R}_{5}=\mathrm{R}_{6}=\mathrm{H}$. (ii) Compound QN2 where $\mathrm{R}_{2}=\mathrm{Cl}, \mathrm{R}_{4}=$ Methyl $\left(\mathrm{CH}_{3}\right) ; \mathrm{R}_{1}=\mathrm{R}_{3}=\mathrm{R}_{5}=$ $\mathrm{R}_{6}=\mathrm{H}$. (iii) Compound $\mathbf{Q N 3}$ where $\mathrm{R}_{1}=$ Hydroxymethyl $\left(\mathrm{CH}_{2} \mathrm{OH}\right) ; \mathrm{R}_{1}=\mathrm{R}_{2}=\mathrm{R}_{3}=\mathrm{R}_{4}=\mathrm{R}_{5}=\mathrm{H}$. (iv) Compound QN4 where $\mathrm{R}_{1}=$ Hydroxymethyl $\left(\mathrm{CH}_{2} \mathrm{OH}\right)$ and $\mathrm{R}_{5}=$ Methyl $\left(\mathrm{CH}_{3}\right) ; \quad \mathrm{R}_{2}=\mathrm{R}_{3}=\mathrm{R}_{4}=\mathrm{R}_{6}=\mathrm{H}$. (v) Compound QN5 where $\mathrm{R}_{1}=$ Chloromethyl $\left(\mathrm{CH}_{2} \mathrm{Cl}\right)$ and $\mathrm{R}_{4}=$ Methyl $\left(\mathrm{CH}_{3}\right), \quad \mathrm{R}_{2}=\mathrm{R}_{3}=\mathrm{R}_{5}=\mathrm{R}_{6}=\mathrm{H}$. (vi) Compound QN6 where $\mathrm{R}_{1}=$ Chloromethyl $\left(\mathrm{CH}_{2} \mathrm{Cl}\right)$ and $\mathrm{R}_{6}=$ Methyl $\left(\mathrm{CH}_{3}\right), \mathrm{R}_{2}=\mathrm{R}_{3}=\mathrm{R}_{4}=\mathrm{R}_{5}=\mathrm{H}$. mers was extracted with dichloromethane. The pure required isomer product QN1 was obtained through column chromatography, ethyl acetate/petroleum ether was used as the eluant. Routine IR, NMR and Mass analysis confirmed the formation of compound QN1. Single crystals of suitable quality for single crystal X-ray diffraction were grown by solvent evaporation technique from 1:1 mixture of ethyl acetate/hexane solvents.

\section{1b Compound QN2: 2,4-dichloro 6-methyl-} quinoline: 4-Methylaniline ( $1 \mathrm{mmol})$, malonic acid $(1 \mathrm{mmol})$ and $10 \mathrm{ml}$ of dry $\mathrm{POCl}_{3}$ were taken in a RB flask and the resulting mixture was heated at $453 \mathrm{~K}$ for $1 \mathrm{~h}$. Entire experimental procedure was same as in QN1.

\section{1c Compound QN3: 2-Chloro-(quinolin-3-yl)} methanol: 2-Chloro-3-formylquinoline $(1 \mathrm{mmol})$, sodium borohydride $(1 \mathrm{mmol})$ and catalytic amount of montmorillonite K-10 were taken in an open vessel and the resulting mixture was irradiated at $500 \mathrm{~W}$ in a domestic microwave oven for $4-5 \mathrm{~min}$. Ethylacetate was poured into the reaction mixture and the catalyst was filtered off. The filtrate was subjected to column chromatography and ethyl acetate/petroleum ether was used as the eluant. IR, NMR and Mass analysis confirmed the formation of compound QN3. Single crystals of suitable quality for single crystal $\mathrm{X}$-ray diffraction were grown by solvent evaporation technique from chloroform.

2.1d Compound QN4: 2-Chloro-(7-methylquinolin3-yl) methanol: 2-Chloro-7-methylquinoline-3-carbaldehyde $(1 \mathrm{mmol})$, sodium borohydride $(1 \mathrm{mmol})$ and catalytic amount of montmorillonite K-10 were taken in an open vessel and the resulting mixture was irradiated at $500 \mathrm{~W}$ in a domestic microwave oven for 4-5 $\mathrm{min}$. The experimental procedure was similar to compound QN1.

2.1e Compound QN5: 2-Chloro-3-(chloromethyl)6-methylquinoline: $2 \mathrm{~mL}$ of thionyl chloride was added to 2-chloro-(6-methylquinolin-3-yl) methanol $(0.5 \mathrm{mmol})$ and refluxed at $349 \mathrm{~K}$ for $30 \mathrm{~min}$. The progress of the reaction was monitored by thin layer chromatography (TLC). After the completion of reaction, the reaction mixture was cooled and transferred into the crushed ice. The precipitate was filtered and dried in air. The compound was purified by column chromatography using petroleum ether as the eluant. IR, NMR and Mass analysis confirmed the forma- 
Table 1. Crystallographic and refinement details for the structures.

\begin{tabular}{|c|c|c|c|}
\hline Compound & QN1 & QN2 & QN3 \\
\hline Crystal size (mm) & $0.28 \times 0.21 \times 0.12$ & $0.26 \times 0.21 \times 0.17$ & $0.24 \times 0.18 \times 0.15$ \\
\hline CCDC number & 756830 & 731569 & 705547 \\
\hline Molecular Formula & $\mathrm{C}_{10} \mathrm{H}_{7} \mathrm{~N}_{1} \mathrm{Cl}_{2}$ & $\mathrm{C}_{10} \mathrm{H}_{7} \mathrm{~N}_{1} \mathrm{Cl}_{2}$ & $\mathrm{C}_{10} \mathrm{H}_{8} \mathrm{~N}_{1} \mathrm{O}_{1} \mathrm{Cl}_{1}$ \\
\hline $\begin{array}{l}\text { Formula weight } \\
\left(\mathrm{g} \mathrm{mol}^{-1}\right)\end{array}$ & 212.07 & 212.07 & 193.62 \\
\hline Temperature (K) & $295(2)$ & $295(2)$ & $295(2)$ \\
\hline Wavelength $(\AA)$ & 0.71073 & 0.71073 & 0.71073 \\
\hline Absorption correction & Multi-scan & Multi-scan & Multi-scan \\
\hline$\mu\left(\mathrm{mm}^{-1}\right)$ & $0 \cdot 650$ & 0.629 & $0 \cdot 398$ \\
\hline Crystal system & Monoclinic & Triclinic & Triclinic \\
\hline Space group & $P 2_{1} / c$ & $P-1$ & $P-1$ \\
\hline$a(\AA)$ & $6 \cdot 8668(2)$ & $7 \cdot 1525(2)$ & $7 \cdot 1181(5)$ \\
\hline$b(\AA)$ & $12 \cdot 9735(3)$ & $11.5551(3)$ & $7 \cdot 3518(5)$ \\
\hline$c(\AA)$ & $10 \cdot 4447(2)$ & $11.9852(3)$ & $9 \cdot 1811(6)$ \\
\hline$\alpha\left({ }^{\circ}\right)$ & 90 & $90 \cdot 168(2)$ & $92.803(4)$ \\
\hline$\beta\left(^{\circ}\right)$ & $98.476(3)$ & $106 \cdot 152(3)$ & $106 \cdot 624(3)$ \\
\hline$\gamma\left({ }^{\circ}\right)$ & 90 & $91 \cdot 090(2)$ & $109 \cdot 900(4)$ \\
\hline Volume $\left(\AA^{3}\right)$ & $920 \cdot 33(4)$ & $951 \cdot 25(5)$ & $427 \cdot 14(5)$ \\
\hline$Z$ & 4 & 4 & 2 \\
\hline Density $\left(\mathrm{g} \mathrm{cm}^{-3}\right)$ & 1.531 & 1.481 & 1.505 \\
\hline$F(000)$ & 432 & 432 & 200 \\
\hline$\theta(\min , \max )$ & $2 \cdot 52,26$ & $3 \cdot 00,25 \cdot 49$ & $2 \cdot 35,25 \cdot 50$ \\
\hline$h_{\min , \max }$ & $(-8,8)$ & $(-8,8)$ & $(-8,8)$ \\
\hline$k_{\min , \max }$ & $\left(\begin{array}{ll}-16 & 15\end{array}\right)$ & $(-13,13)$ & $(-8,8)$ \\
\hline$l_{\min , \max }$ & $(-12,12)$ & $(-14,14)$ & $(-11,10)$ \\
\hline No. of measured reflections & 9527 & 18705 & 6896 \\
\hline No. of unique reflections & 1810 & 3542 & 1578 \\
\hline No. of parameters & 119 & 237 & 119 \\
\hline$R_{\text {(int) }}$ & 0.0321 & 0.0310 & 0.0206 \\
\hline$R \_$all, $R \_$obs & $0.0516,0.0328$ & $0.0531,0.0376$ & $0.0317,0.0287$ \\
\hline$w \bar{R}_{2}$ all, $w R_{2}$ obs & $0 \cdot 0850,0.0802$ & $0 \cdot 1082,0 \cdot 1038$ & $0.0792,0.0775$ \\
\hline$\Delta \rho_{\min , \max }^{-}\left(\mathrm{e} \bar{\AA}^{-3}\right)$ & $-0.244,0.213$ & $-0 \cdot 227,0 \cdot 209$ & $-0 \cdot 268,0 \cdot 163$ \\
\hline G.o.F & 1.032 & 1.067 & $1 \cdot 119$ \\
\hline Compound & QN4 & QN5 & QN6 \\
\hline Crystal size (mm) & $0.40 \times 0.15 \times 0.10$ & $0.35 \times 0.31 \times 0.21$ & $0.21 \times 0.16 \times 0.12$ \\
\hline CĆDC number & 725752 & 731573 & 746771 \\
\hline Molecular formula & $\mathrm{C}_{11} \mathrm{H}_{10} \mathrm{~N}_{1} \mathrm{O}_{1} \mathrm{Cl}_{1}$ & $\mathrm{C}_{11} \mathrm{H}_{9} \mathrm{~N}_{1} \mathrm{Cl}_{2}$ & $\mathrm{C}_{11} \mathrm{H}_{9} \mathrm{~N}_{1} \mathrm{Cl}_{2}$ \\
\hline Formula weight $\left(\mathrm{g} \mathrm{mol}^{-1}\right)$ & $207 \cdot 65$ & $226 \cdot 09$ & $226 \cdot 09$ \\
\hline Temperature (K) & $295(2)$ & $295(2)$ & $295(2)$ \\
\hline Wavelength $(\AA)$ & 0.71073 & 0.71073 & 0.71073 \\
\hline Absorption correction & Multi-scan & Multi-scan & Multi-scan \\
\hline$\mu\left(\mathrm{mm}^{-1}\right)$ & 0.356 & 0.588 & 0.578 \\
\hline Crystal system & Monoclinic & Triclinic & Monoclinic \\
\hline Space group & $P 2_{1} / c$ & $P-1$ & $P 2_{1} / c$ \\
\hline$a(\AA)$ & $19 \cdot 978(2)$ & $6 \cdot 6003(8)$ & $15 \cdot 1752(3)$ \\
\hline$b(\AA)$ & $7 \cdot 2814(12)$ & $7 \cdot 6250(10)$ & $4.6020(1)$ \\
\hline$c(\AA)$ & $13.7772(13)$ & $11 \cdot 1333(14)$ & $14.9781(3)$ \\
\hline$\alpha\left({ }^{\circ}\right)$ & 90 & $84 \cdot 018(2)$ & 90 \\
\hline$\beta\left({ }^{\circ}\right)$ & $104 \cdot 593(10)$ & $74.507(2)$ & $94 \cdot 357(2)$ \\
\hline$\gamma\left({ }^{\circ}\right)$ & 90 & $71 \cdot 764(2)$ & 90 \\
\hline Volume $\left(\AA^{3}\right)$ & $1939 \cdot 5(4)$ & $512 \cdot 70(11)$ & $1042 \cdot 99(4)$ \\
\hline Z & 8 & 2 & 4 \\
\hline Density $\left(\mathrm{g} \mathrm{cm}^{-3}\right)$ & 1.422 & 1.465 & 1.440 \\
\hline$F(000)$ & 864 & 232 & 464 \\
\hline$\theta(\min , \max )$ & $3 \cdot 06,25 \cdot 50$ & $1 \cdot 90,25 \cdot 50$ & $3 \cdot 13,26 \cdot 00$ \\
\hline
\end{tabular}


Table 1. (Contd...)

\begin{tabular}{llll}
\hline Compound & \multicolumn{1}{c}{ QN4 } & \multicolumn{1}{c}{ QN5 } & \multicolumn{1}{c}{ QN6 } \\
\hline$h_{\min , \max }$ & $(-23,24)$ & $(-7,7)$ & $(-18,18)$ \\
$k_{\min , \max }$ & $(-8,8)$ & $(-9,9)$ & $(-5,5)$ \\
$l_{\min , \max }$ & $(-16,16)$ & $(-13,13)$ & $(-18,18)$ \\
No. of measured reflections & 19752 & 5078 & 9881 \\
No. of unique reflections & 3600 & 1895 & 2051 \\
No. of parameters & 257 & 128 & 128 \\
$R_{\text {(int) }}$ & $0 \cdot 0632$ & $0 \cdot 0168$ & $0 \cdot 0192$ \\
$R$ all, $R$ obs & $0 \cdot 0851,0 \cdot 0428$ & $0.0391,0.0346$ & $0 \cdot 0406,0 \cdot 0312$ \\
$w R_{2}$ all, $w R_{2}$ obs & $0 \cdot 1089,0 \cdot 1005$ & $0.0941,0.0916$ & $0 \cdot 0974,0 \cdot 0942$ \\
$\Delta \rho_{\min , \max }\left(\mathrm{e} \AA^{-3}\right)$ & $-0 \cdot 199,0 \cdot 230$ & $-0 \cdot 302,0 \cdot 195$ & $-0 \cdot 205,0 \cdot 177$ \\
G.o.F & 0.906 & 1.042 & $1 \cdot 136$ \\
\hline
\end{tabular}

Table 2. Intermolecular $\mathrm{Cl} \ldots \mathrm{Cl}$ contacts in studied six compounds.

\begin{tabular}{|c|c|c|c|c|c|}
\hline Compound & $\mathrm{C}-\mathrm{X}_{1} \ldots \mathrm{X}_{2}-\mathrm{C}$ & $\mathrm{X}_{1} \ldots \mathrm{X}_{2} \AA$ & $\begin{array}{c}\angle \mathrm{C}-\mathrm{X}_{1} \ldots \mathrm{X}_{2}^{\circ} \\
\left(\theta_{1}\right)\end{array}$ & $\begin{array}{c}\angle \mathrm{X}_{1} \ldots \mathrm{X}_{2}-\mathrm{C}^{\circ} \\
\left(\theta_{2}\right)\end{array}$ & Symmetry operation \\
\hline QN1 & $\mathrm{C} 1-\mathrm{Cl1} \ldots \mathrm{Cl1}-\mathrm{C} 1$ & $3 \cdot 545(2)$ & $144 \cdot 0$ & $144 \cdot 0$ & $-x+1,-y+2,-z-1$ \\
\hline \multirow[t]{2}{*}{ QN2 } & $\mathrm{C} 3 \mathrm{~A}-\mathrm{Cl} 2 \mathrm{~A} \ldots \mathrm{Cl1B}-\mathrm{C} 1 \mathrm{~B}$ & $3.662(1)$ & $168 \cdot 0$ & $107 \cdot 2$ & $x, y-1, z+1$ \\
\hline & $\mathrm{C} 3 \mathrm{~B}-\mathrm{Cl} 1 \mathrm{~A} \ldots \mathrm{Cl} 2 \mathrm{~B}-\mathrm{C} 1 \mathrm{~A}$ & $3 \cdot 813(1)$ & $156 \cdot 8$ & $109 \cdot 1$ & $x, y, z+1$ \\
\hline QN3 & $\mathrm{C} 1-\mathrm{Cl1} \ldots \mathrm{Cl1}-\mathrm{C} 1$ & $3.661(2)$ & $150 \cdot 4$ & $150 \cdot 4$ & $-x+1,-y+2,-z+1$ \\
\hline QN4 & $\mathrm{C} 1 \mathrm{~B}-\mathrm{C} 11 \mathrm{~B} \ldots \mathrm{C} 11 \mathrm{~A}-\mathrm{C} 1 \mathrm{~A}$ & $3 \cdot 546(1)$ & $142 \cdot 2$ & $122 \cdot 5$ & $x-1,-y+1 / 2, z+1 / 2$ \\
\hline \multirow[t]{3}{*}{ QN5 } & $\mathrm{C} 10-\mathrm{Cl} 2 \ldots \mathrm{Cl} 2 \ldots \mathrm{C} 10$ & $3 \cdot 613(1)$ & $155 \cdot 6$ & $155 \cdot 6$ & $-x+2,-y,-z$ \\
\hline & $\mathrm{C} 1-\mathrm{Cl1} \ldots \mathrm{Cl} 2-\mathrm{C} 10$ & $3 \cdot 614(2)$ & $167 \cdot 5$ & $100 \cdot 1$ & $-x+1,-y+1,-z$ \\
\hline & $\mathrm{C} 1-\mathrm{Cl1} \ldots \mathrm{Cl1}-\mathrm{C} 1$ & $3 \cdot 575(2)$ & $132 \cdot 0$ & $132 \cdot 0$ & $-x+1,-y+1,-z$ \\
\hline QN6 & $\mathrm{C} 10-\mathrm{Cl} 2 \ldots \mathrm{Cl1}-\mathrm{C} 1$ & $3 \cdot 538(1)$ & $167 \cdot 8$ & $104 \cdot 9$ & $-x+1,-y+2,-z+1$ \\
\hline
\end{tabular}

tion of compound QN5. Single crystals of suitable quality for single crystal X-ray diffraction were grown by solvent evaporation technique from chloroform.

2.1f Compound QN6: 2-Chloro-3-(chloromethyl)8-methylquinoline: To 2-chloro-(8-methylquinolin3 -yl) methanol $(0.5 \mathrm{mmol}), 2 \mathrm{~mL}$ of thionyl chloride was added and refluxed at $349 \mathrm{~K}$ for $30 \mathrm{~min}$. The workup procedure was similar to compound QN5.

\section{$2.2 X$-ray diffraction}

The single crystal X-ray diffraction data of all crystals were collected on an Oxford Xcalibur (Mova) diffractometer with Eos CCD detector. ${ }^{17}$ The X-ray generator was operated at $50 \mathrm{kV}$ and $1 \mathrm{~mA}$ using Enhanced MoK $\alpha$ radiation. Data were collected with $\omega$ scan width of $1^{\circ}$. The data reduction, an empirical absorption correction and space group determination were done using CrysAlisPro RED of Oxford Diffraction. ${ }^{17}$ The crystal structures were solved by direct method using either SIR92 ${ }^{18}$ or SHELXS ${ }^{19}$ and refined by full matrix least-squares method using SHELXL97, ${ }^{19}$ present in the program suite WinGx (version 1.63.04a) ${ }^{20}$ The molecular diagrams were generated using POV-ray (version 3.6) (1) $^{21}$ and the packing diagrams were generated using CAMERON. $^{22}$ Geometrical calculations were done using PARST $95^{23}$ and PLATON. ${ }^{24}$ The positions of all hydrogen atoms were fixed geometrically and refined isotropically using the riding hydrogen atom model. The details of the data collection and refinement are given in table $1, \mathrm{Cl} \ldots \mathrm{Cl}$ contacts and other intermolecular interactions are listed in tables 2 and 3 , respectively.

\section{Result and discussion}

\subsection{Structure of 2,4-dichloro 5-methylquinoline (QN1)}

The substitution of methyl moiety to 2-chloroquinoline structure at position $\mathrm{R}_{3}$ resulted in compound QN1 (scheme 2), which crystallizes in the space group $P 2_{1} / c$ with $Z=4$. Figure la gives the ORTEP diagram of QN1 with ellipsoids drawn at $50 \%$ probability. Intermolecular $\mathrm{Cl} \ldots \mathrm{Cl}$ contacts of Type I trans geometry (figure $1 \mathrm{~b}$, table 2 ) along with 
Table 3. Intermolecular interactions in studied six compounds.

\begin{tabular}{|c|c|c|c|c|c|c|}
\hline Crystal & $\mathrm{D}-\mathrm{H} \ldots \mathrm{A}$ & $\mathrm{D}-\mathrm{H} / \AA$ & $\mathrm{H} \ldots \mathrm{A} / \AA$ & $\mathrm{D} \ldots \mathrm{A} / \AA$ & $\angle \mathrm{D}-\mathrm{H} \ldots \mathrm{A} /^{\circ}$ & Symmetry \\
\hline QN1 & C6-H6 ...N1 & 0.930 & $2 \cdot 610$ & $3 \cdot 530(1)$ & $169 \cdot 0$ & $x,-y+1 / 2+1, z+1 / 2$ \\
\hline QN2 & $\mathrm{C} 10 \mathrm{~A}-\mathrm{H} 10 \mathrm{C} \ldots \mathrm{Cl} 2 \mathrm{~B}$ & $0 \cdot 960$ & $2 \cdot 956$ & $3 \cdot 719(2)$ & $137 \cdot 0$ & $-x,-y+1,-z$ \\
\hline \multirow[t]{3}{*}{ QN3 } & $\mathrm{O} 1-\mathrm{H} 1 \mathrm{O} \ldots \mathrm{N} 1$ & $0 \cdot 820$ & $2 \cdot 220$ & $2 \cdot 956(2)$ & $149 \cdot 0$ & $x-1, y, z$ \\
\hline & $\mathrm{C} 4-\mathrm{H} 4 \ldots \mathrm{O} 1$ & $0 \cdot 930$ & $2 \cdot 685$ & $3 \cdot 146(2)$ & $136 \cdot 0$ & $-x,-y+1,-z+2$ \\
\hline & $\mathrm{C} 10-\mathrm{H} 10 \mathrm{~A} \ldots \mathrm{Cg}(2)$ & $0 \cdot 970$ & $2 \cdot 790$ & $3 \cdot 689(1)$ & $154 \cdot 0$ & $-x+1,-y+2,-z$ \\
\hline \multirow[t]{4}{*}{ QN4 } & O1A-H1OA...N1A & $0 \cdot 820$ & $2 \cdot 160$ & $2 \cdot 921(2)$ & $155 \cdot 0$ & $x,-y+1 / 2, z+1 / 2$ \\
\hline & O1B-H1OB ...N1B & $0 \cdot 820$ & $2 \cdot 220$ & $2 \cdot 978(3)$ & $153 \cdot 0$ & $x,-y+1 / 2+1, z+1 / 2-1$ \\
\hline & C11A-H11A...O1A & 0.960 & $2 \cdot 650$ & $3 \cdot 420(3)$ & $137 \cdot 0$ & $-x+1, y-1 / 2, z+1 / 2+1$ \\
\hline & C4B-H4B ... O1B & 0.930 & $2 \cdot 689$ & $3 \cdot 454(3)$ & $140 \cdot 0$ & $-x+2,-y+1,-z+1$ \\
\hline QN5 & C10-H10A...Cl1 & 0.970 & $2 \cdot 868$ & $3 \cdot 747(2)$ & $151 \cdot 0$ & $x+1, y, z$ \\
\hline \multirow[t]{2}{*}{ QN6 } & $\mathrm{C} 10-\mathrm{H} 10 \mathrm{~B} \ldots \mathrm{Cl} 2$ & 0.970 & $2 \cdot 942$ & $3 \cdot 899(2)$ & $169 \cdot 0$ & $-x+1, y+1 / 2,-z+1 / 2+1$ \\
\hline & $\mathrm{C} 10-\mathrm{H} 10 \mathrm{~A} \ldots \mathrm{Cg}(1)$ & 0.970 & $2 \cdot 970$ & $3 \cdot 563(2)$ & $121 \cdot 0$ & $x, y-1, z$ \\
\hline
\end{tabular}

In compound $\mathbf{Q N 3}, \mathrm{Cg}(2)$ is centroid of $\mathrm{C} 4 / \mathrm{C} 9$ ring whereas in compound $\mathbf{Q N 6}, \mathrm{Cg}(1)$ is centroid of $\mathrm{N} 1-\mathrm{C} 1-\mathrm{C} 2-\mathrm{C} 3-$ C9-C8 ring.
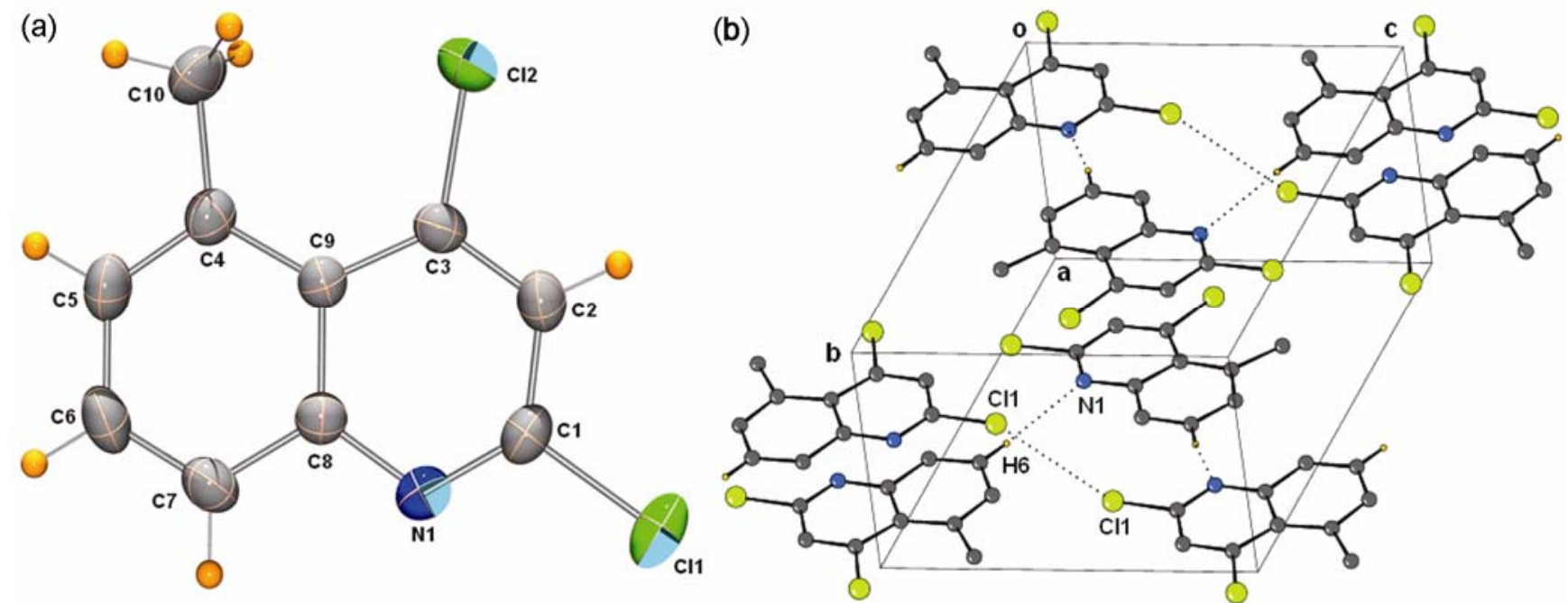

Figure 1. (a) ORTEP of compound QN1 drawn with $50 \%$ ellipsoidal probability. (b) Packing diagram of compound QN1 depicting intermolecular $\mathrm{Cl} \ldots \mathrm{Cl}$ contacts and $\mathrm{C}-\mathrm{H} \ldots \mathrm{N}$ hydrogen bonds.

an intermolecular $\mathrm{C}-\mathrm{H} \ldots \mathrm{N}$ hydrogen bond (table 3) hold the molecules together in the crystal lattice. This results in a parallel arrangement of molecules generation $\pi \ldots \pi$ stacking interactions with a separation distance of 3.614(1)-3.724(2) $\AA$ between aromatic rings leading to further stabilization of the crystal structure.

\subsection{Structure of 2,4-dichloro 6-methylquinoline (QN2)}

Compound QN2 is an isomer of compound QN1 with the methyl group now at position $\mathrm{R}_{4}$ (scheme 2). The cell parameters are almost identical to QN1 and the compound crystallizes in a triclinic P-1 space group with two independent molecules in the asymmetric unit. The ORTEP diagram of QN2 (figure $2 \mathrm{a}$ ) shows the two independent molecules and the dihedral angle between the least squares planes of these molecules is $15 \cdot 88(2)^{\circ}$. $\mathrm{Cl} \ldots \mathrm{Cl}$ intermolecular interactions develop between $\mathrm{CllA}$ and $\mathrm{Cl} 2 \mathrm{~B}$ (figure $2 \mathrm{~b}$, table 2 ) connecting the two independent molecules in a two-dimensional motif through the entire crystal. An additional short $\mathrm{Cl} \ldots \mathrm{Cl}$ contact (slightly larger than the van der Waal radii sum, table 2) develops as a consequence. Indeed this contact appears as a surrogate to the $\mathrm{C}-\mathrm{H}$... $\mathrm{Cl}$ interaction (figure $2 \mathrm{~b}$ ). $\pi \ldots \pi$ stacking interactions of 3.578(1)-3.768(2) $\AA$ between aromatic rings stabilize the packing in the lattice. It is noteworthy 
that the nitrogen atom does not participate in an intermolecular interaction like in QN1.

\subsection{Structure of 2-Chloro-(quinolin-3-yl) methanol (QN3)}

The substitution of hydroxymethyl group at the position $\mathrm{R}_{1}$ of 2-chloroquinoline gives compound QN3 (scheme 2) which crystallizes in the space group P-1 with $Z=2$ (figure $3 \mathrm{a}$ ). Type $\mathrm{I} \mathrm{Cl} \ldots \mathrm{Cl}$ contacts with trans geometry (figure $3 \mathrm{~b}$ ) hold the molecules together along with strong intermolecular $\mathrm{O}-\mathrm{H} \ldots \mathrm{N}$ and $\mathrm{C}-\mathrm{H} \ldots \mathrm{O}$ hydrogen bonds (figure $3 \mathrm{~b}$, table 3 ). $\mathrm{C}-\mathrm{H} \ldots \pi$ (figure $3 \mathrm{~b}$, table 3 ) interactions provide further stability by holding molecular dimers across the centre of inversion. $\pi \ldots \pi$ aromatic stacking interactions of 3.674(1)-3.774(1) $\AA$ between aromatic rings exist as in the previous cases.

\subsection{Structure of 2-Chloro-(7-methylquinolin-3-yl) methanol (QN4)}

The substitution of an additional methyl group at position $\mathrm{R}_{3}$ to $\mathbf{Q N 3}$ gives compound QN4 (scheme 2,
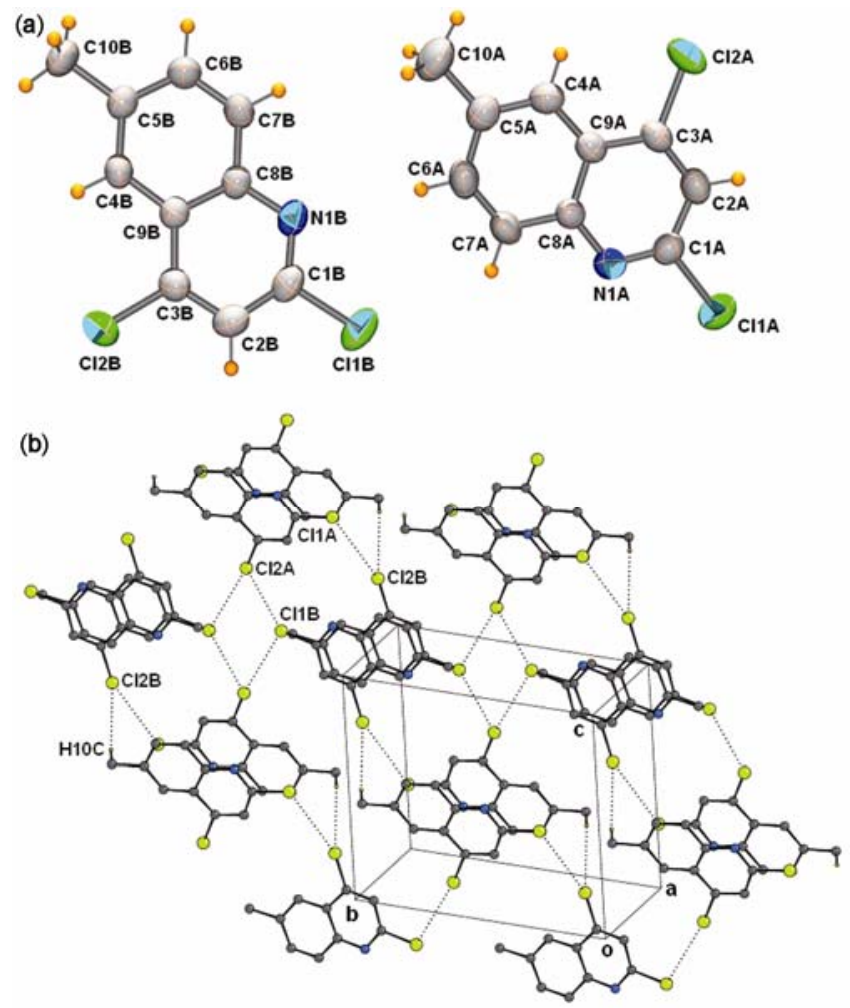

Figure 2. (a) ORTEP of compound QN2 drawn with $50 \%$ ellipsoidal probability. (b) Packing diagram of compound $\mathbf{Q N 2}$ depicting intermolecular $\mathrm{Cl} \ldots \mathrm{Cl}$ contacts and $\mathrm{C}-\mathrm{H}$... $\mathrm{Cl}$ hydrogen bonds. figure 4a), which crystallizes in the space group $P 2_{1} / c$ with $Z=8$ and resulting in two independent molecules at asymmetric unit. The dihedral angle between the least squares plane of two independent molecules in asymmetric unit is $6 \cdot 17(2)^{\circ}$. $\mathrm{Cl} \ldots \mathrm{Cl}$ contacts have Type II geometry, however $\theta_{1}$ and $\theta_{2}$ deviate significantly from the ideal values of Type II contact (figure $4 \mathrm{~b}$, table 2). $\mathrm{O}-\mathrm{H} \ldots \mathrm{N}$ and $\mathrm{C}-\mathrm{H} \ldots \mathrm{O}$ hydrogen bonds add further stability to the packing (figure $4 \mathrm{~b}$, table 3 ). $\pi \ldots \pi$ aromatic stacking interac-
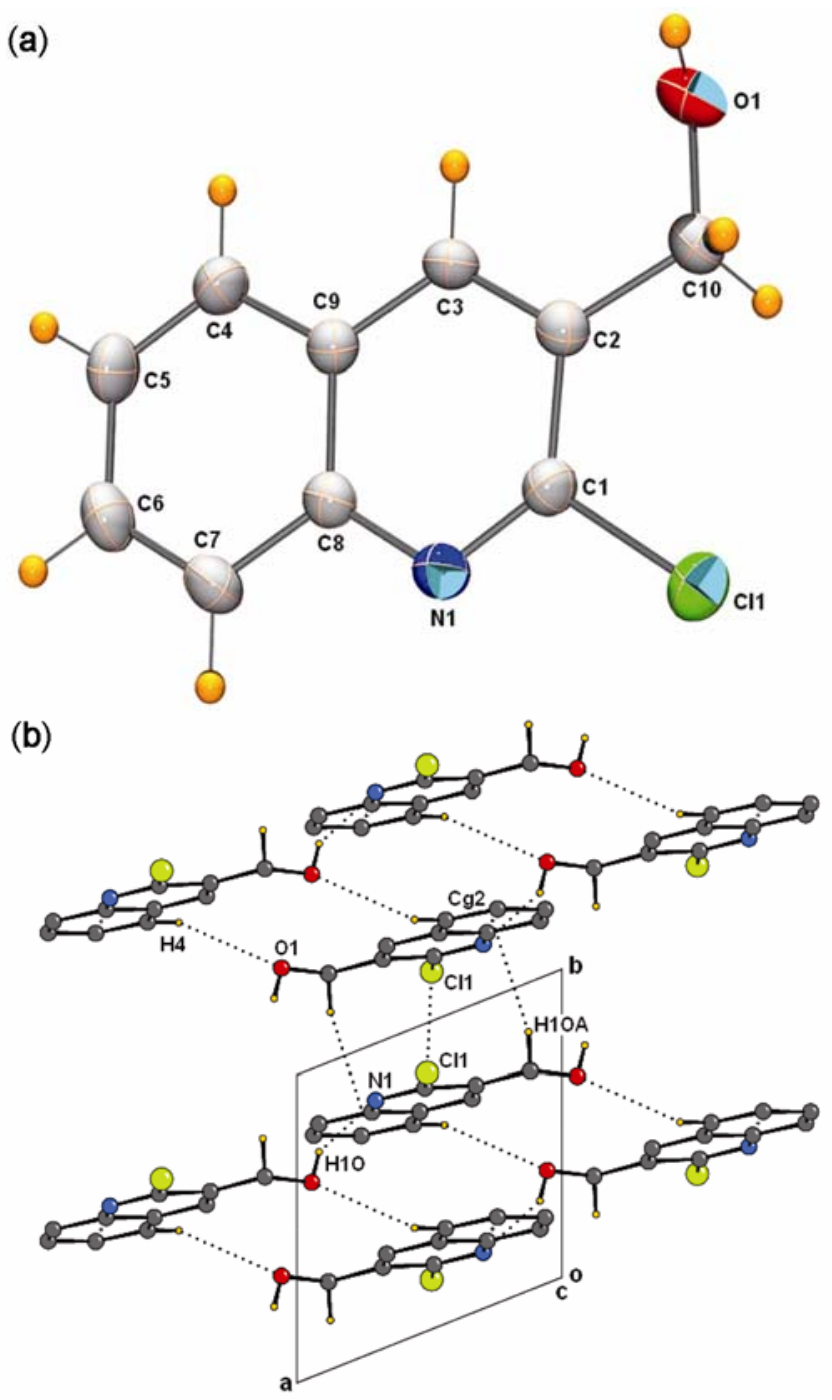

Figure 3. (a) ORTEP of compound QN3 drawn with $50 \%$ ellipsoidal probability. (b) Packing diagram of compound QN3 depicting intermolecular $\mathrm{Cl} \ldots \mathrm{Cl}$ contacts, $\mathrm{O}-\mathrm{H}$... N hydrogen bonds along with $\mathrm{C}-\mathrm{H} \ldots \mathrm{O}$ and $\mathrm{C}-\mathrm{H} \ldots \pi[\mathrm{Cg}(2)]$ interactions which generate molecular dimers. 
tions of 3.842(1)-3.887(2) A between aromatic rings stabilise the packing.

\subsection{2-Chloro-3-(chloromethyl)-6-methylquinoline} (QN5)

The substitution of chloromethyl group at position $\mathrm{R}_{1}$ and methyl group at $\mathrm{R}_{4}$ respectively to 2chloroquinoline resulted in compound QN5 (scheme 2 , figure $5 \mathrm{a}$ ), which crystallises in the space group $\mathrm{P}-1$ with $Z=2$. The crystal structure is stabilized by $\mathrm{Cl} \ldots \mathrm{Cl}$ interactions and $\mathrm{C}-\mathrm{H} \ldots \mathrm{Cl}$ halogen bonds only. $\mathrm{Cl} 1$ and $\mathrm{Cl} 2$ generate 'bifurcated' $\mathrm{Cl} \ldots \mathrm{Cl}$ short contacts resulting in a 'sawtooth' type supramolecular network in the crystal lattice (figure 5b). Both Type I and Type II $\mathrm{Cl} \ldots \mathrm{Cl}$ intermolecular interactions coexist in this structure. The $\mathrm{C}-\mathrm{H}$... $\mathrm{Cl}$ hydrogen bond generates a one dimensional molecular chain along the crystallographic ' $a$ ' axis (figure $5 b$, table 3$). \pi \ldots \pi$ aromatic stacking interactions in the range of 3.718(1)-3.764(2) $\AA$ between aromatic rings provide further stability as in the previous cases.

(a)
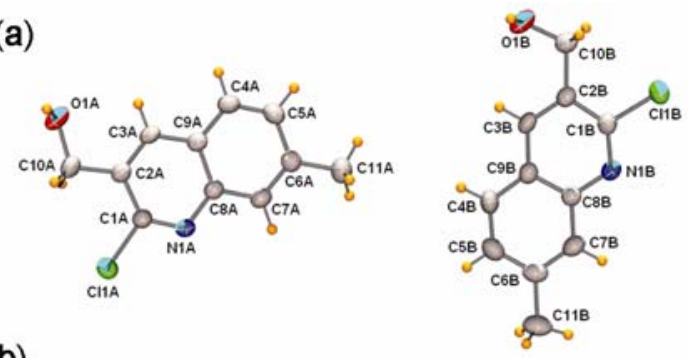

(b)

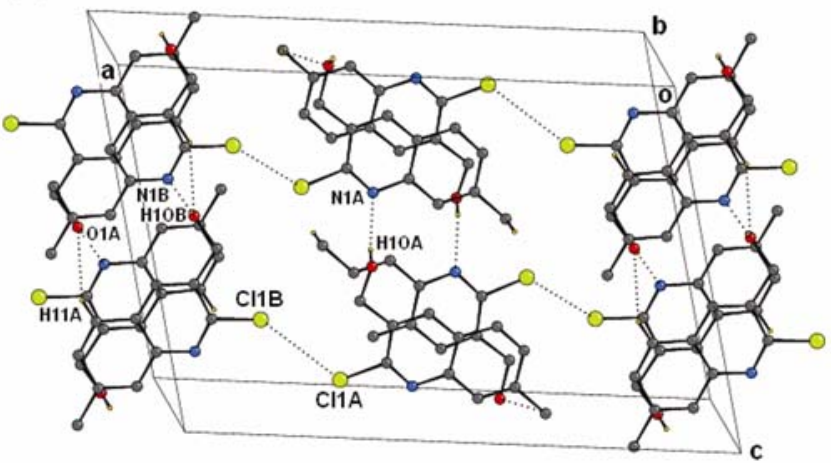

Figure 4. (a) ORTEP of compound QN4 drawn with $50 \%$ ellipsoidal probability. (b) Packing diagram of compound QN4 depicting intermolecular $\mathrm{Cl} \ldots \mathrm{Cl}$ interactions, $\mathrm{O}-\mathrm{H} \ldots \mathrm{N}$ and $\mathrm{C}-\mathrm{H} \ldots \mathrm{O}$ hydrogen bonds.
3.6 Structure of 2-chloro-3-(chloromethyl)-8methylquinoline (QN6)

Compound QN6 is an isomer of compound QN5. (scheme 2). The compound (figure 6a) crystallizes in the space group $P 2_{1} / c$ with $Z=4 . \mathrm{Cl} \ldots \mathrm{Cl}$ interactions with Type II geometry are generated by involving chlorine atoms $\mathrm{Cll}$ and $\mathrm{Cl} 2$, resulted in a molecular dimer formation across the centre of inversion (figure $6 \mathrm{~b}$, table 2). $\mathrm{C}-\mathrm{H} . . \mathrm{Cl}$ hydrogen bonds generate a 'sinusoidal' molecular chain (figure $6 \mathrm{~b}) . \mathrm{C}-\mathrm{H} \ldots \pi$ intermolecular interactions generate a 1D molecular chain as in QN5 while one $\pi \ldots \pi$ stacking interaction of 3.614(1) $\AA$ is conserved in the crystal packing.

\section{Conclusion}

The above studies bring out an interesting feature in substituted 2-chloroquinolines. Type II $\mathrm{Cl} \ldots \mathrm{Cl}$ interactions generate $\mathrm{C}-\mathrm{H} \ldots \mathrm{Cl}$ interactions in the supramolecular assembly in the crystal lattice. This
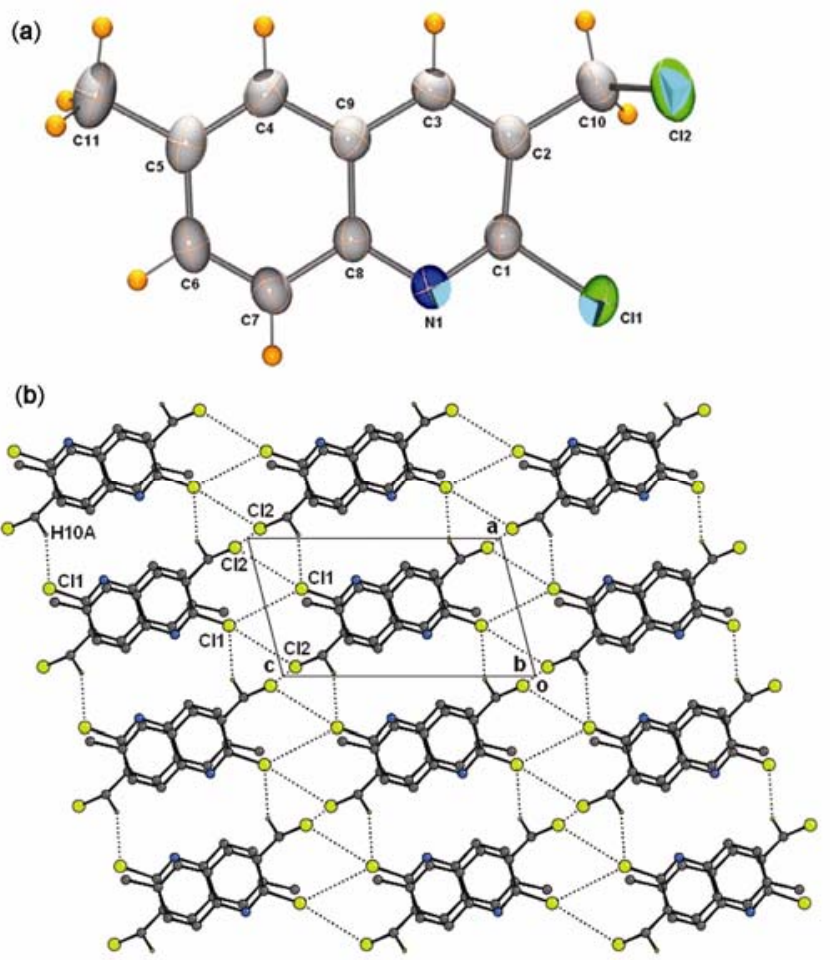

Figure 5. (a) ORTEP of compound QN5 drawn with $50 \%$ ellipsoidal probability. (b) Packing diagram of compound QN5 showing 'bifurcated' $\mathrm{Cl}$... $\mathrm{Cl}$ short contacts generating a 'saw tooth' type network. $\mathrm{C}-\mathrm{H}$... Cl hydrogen bonds form a molecular chain along ' $a$ ' axis. 


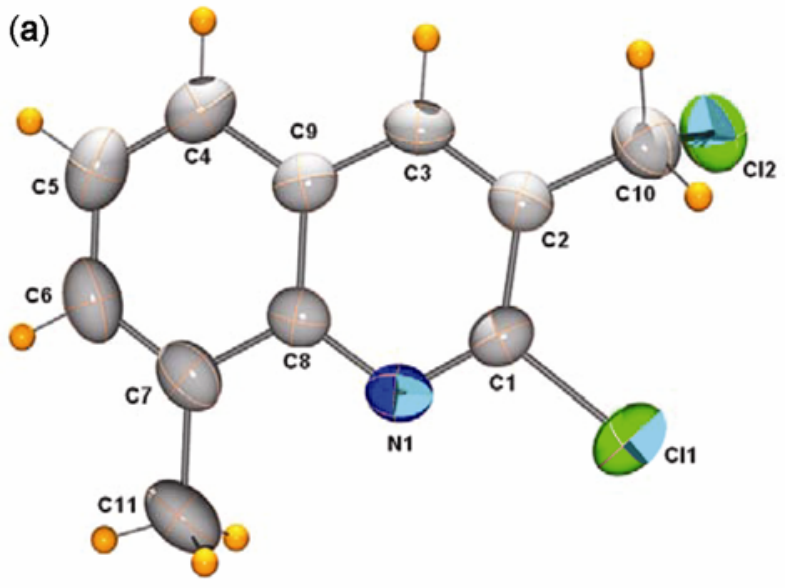

(b)

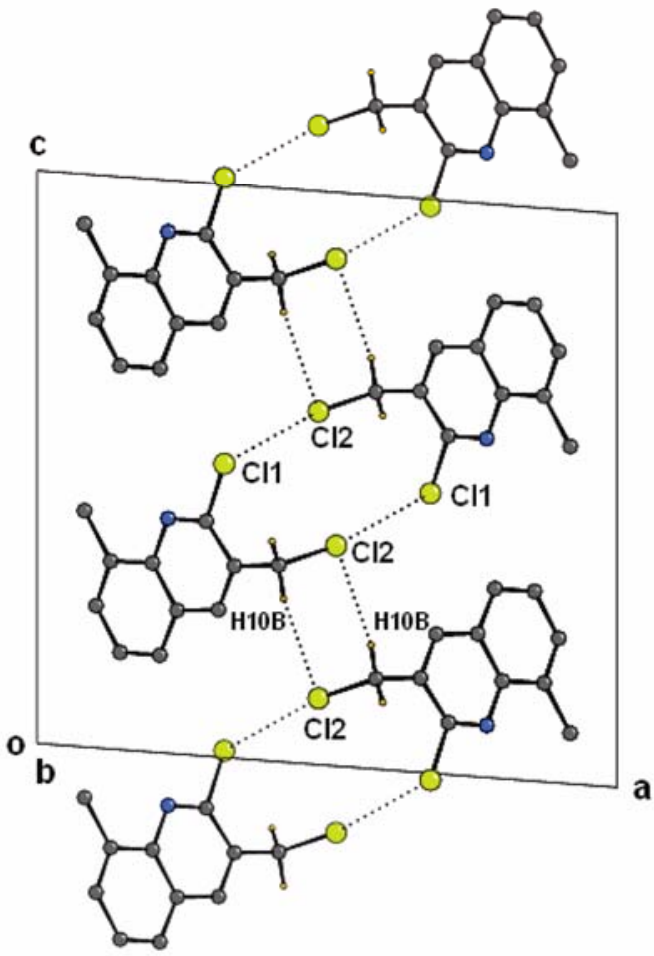

Figure 6. (a) ORTEP of compound QN6 drawn with $50 \%$ ellipsoidal probability. (b) Packing diagram of compound QN6 depicting intermolecular $\mathrm{Cl} \ldots \mathrm{Cl}$ contacts and $\mathrm{C}-\mathrm{H} \ldots \mathrm{Cl}$ hydrogen bonds forming molecular dimmer across the center of inversion.

in fact avoids formation of other types of both weak and strong hydrogen bonds. In all Type I contacts other hydrogen bonds, both strong and weak appear to add stability to the packing features.

\section{Supplementary material}

Crystallographic details (excluding structure factors) on the structure analysis of the all compounds (QN1-QN5) reported in this paper have been depos- ited with the Cambridge Crystallographic Data Center, 12 Union Road, Cambridge, CB2, 1E-Z,UK (Fax: +44-1223-336-033; email: deposit@ccdc.sam.ac.uk). The depository numbers are given in the tables.

\section{Acknowledgements}

We thank Department of Science and Technology (DST), FIST level II for providing the XCaliber Mova Oxford diffraction machine at SSCU, Indian Institute of Science (IISc), Bangalore. FNK thanks DST for Fast Track proposal funding.

\section{References}

1. Desiraju G R and Sarma J A R P 1986 Proc. Indian Acad. Sci., Chem. Sci. 96599

2. Green B S and Schmidt G M J 1971 Israel Chemical Society Annual Meeting Abstracts (Israel Chemical Society) p. 190

3. Awwadi F F, Willett R D, Peterson K A and Twamley B 2006 Chem. Eur. J. 12 8952; Price S L, Stone A J, Lucas J, Rowland R S and Thornley A E 1994 J. Am. Chem. Soc. 1164910

4. Reddy C M, Kirchner M T, Gundakaram R C, Padmanabhan K A and Desiraju G R 2006 Chem. Eur. J. 122222

5. Sakurai T, Sundaralingam M and Jeffrey G A 1963 Acta Crystallogr. 16 354; Ramasubbu N, Parthasarathy R and Murray-Rust P $1986 \mathrm{~J}$. Am. Chem. Soc. 108 4308; Desiraju G R and Parthasarathy R $1989 \mathrm{~J}$. Am. Chem. Soc. 111 8725; Saha B K, Nangia A and Nicoud J F 2006 Cryst. Growth Des. 61278

6. Pedireddi V R, Reddy D S, Goud B S, Craig D C, Rae A D and Desiraju G R 1993 J. Chem. Soc. Perkin Trans. 22353

7. Choudhury A R and Row T N G 2004 Cryst. Growth Des. 4 47; Thalladi V R, Weiss H-C, Bläser D, Boese $\mathrm{R}$, Nangia A and Desiraju G R $1998 \mathrm{~J}$. Am. Chem. Soc. 1208702

8. Chopra D, Cameron T S, Ferrara J D and Row T N G 2006 J. Phys. Chem. A 11010465

9. Garci a P, Dahaoui S, Katan C, Souhassou M and Lecomte C 2007 Faraday Discuss. 135 217; Bui T T T, Dahaoui S, Lecomte C, Desiraju G R and Espinosa E 2009 Angew. Chem. Int. Ed. 483838

10. Nayak S K, Prathapa S J and Row T N G 2009 J. Mol. Struct. 935156

11. Cairns H, Cox D, Gould $\mathrm{K}$ J, Ingall $\mathrm{A} H$ and Suschitzky J L 1985 J. Med. Chem. 281832

12. Jain R, Jain S, Gupta R C, Anand N, Dutta G P and Puri S K 1994 Indian J. Chem. B33 251

13. Mohammed A, Abdel-Hamid N, Maher F and Farghaly A 1992 Czech. Chem. Comm. 571547

14. Croisy-Delcey M, Coroisy A, Carrez D, Huel C, Chiaroni A, Ducrot P, Bisagni E, Jin L and Leclercq G 2000 Bioorg. Med. Chem. 82629 
15. Dlugosz A and Dus D 1996 Farmaco 51367

16. Abadi A H, Brun R and Arzneimforsch 2003 Drug Res. 53655

17. Oxford Diffraction 2009, CrysAlisPro CCD and CrysAlisPro RED. Versions 1.171.33.41. Oxford Diffraction Ltd., Abingdon, Oxfordshire, England

18. Altomare A, Cascarano G, Giacovazzo $\mathrm{C}$ and Guagliardi A 1993 J. Appl. Crystallogr. 26343

19. Sheldrick G M 2008 Acta Crystallogr. Sect. A 64112
20. Farrugia L J 1999 J. Appl. Crystallogr. 32837

21. The POV-Ray Team, 2004. POV-Ray - The persistence of vision raytracer; http://www.povray.org

22. Watkin D M, Pearce L and Prout C K 1993 CAMERON - A Molecular Graphics Package, Chemical Crystallography Laboratory, Oxford, University of Oxford

23. Nardelli M 1995 J. Appl. Crystallogr. 28569

24. Spek A L 2003 J. Appl. Crystallogr. 367 